\title{
Insecticide resistance in malaria vectors in Kumasi, Ghana
}

\author{
Sandra Baffour-Awuah ${ }^{1,2^{*}}$, Augustina A. Annan ${ }^{1,2}$, Oumou Maiga-Ascofare ${ }^{1,3}$, Soma Diloma Dieudonné4, \\ Priscilla Adjei-Kusi ${ }^{1}$, Ellis Owusu-Dabo ${ }^{1,5}$ and Kwasi Obiri-Danso ${ }^{2}$
}

\begin{abstract}
Background: There have been recent reports of surge in resistance to insecticides in pocketed areas in Ghana necessitating the need for information about local vector populations and their resistance to the insecticides approved by the World Health Organization (WHO). We therefore studied a population of malaria vectors from Kumasi in the Ashanti Region of Ghana and their resistance to currently used insecticides. We conducted susceptibility tests to the four major classes of insecticides by collecting larvae of anopheline mosquitoes from several communities in the region. Surviving adults from these larvae were then subjected to the WHO-approved susceptibility tests and characterization of knockdown resistance and acetylcholinesterase mutant genes.

Results: Out of 619 Anopheles specimens sampled, 537 (87\%) were identified as Anopheles gambiae (sensu stricto), which was also the species with the lowest knockdown resistance mutant gene, $61 \%(P=0.017)$. Knockdown resistance mutant gene was as high as $91 \%$ in An. coluzzii. Mosquitoes collected showed susceptibility ranging from $98-100 \%$ to organophosphates, 38-56\% to carbamates and $15-47 \%$ and $38-46 \%$ to pyrethroids and organochlorides, respectively. The knockdown resistance mutation frequency of Anopheles gambiae (sensu lato) mosquitoes that were exposed to both pyrethroids and organochlorides was 404 (65\%). Acetylcholinesterase mutant gene was not found in this population of vectors.
\end{abstract}

Conclusion: Our study shows that pyrethroids have the highest level of resistance in the population of mosquito vectors studied probably due to their frequent use, especially in impregnation of insecticide-treated nets and in insecticides used to control pests on irrigated vegetable farms. We recommend studies to monitor trends in the use of all insecticides and of pyrethroids in particular.

Keywords: Malaria, Anopheles, Resistance, Vector control, Urban area

\section{Background}

Malaria is transmitted by different Anopheles species and its occurrence and intensity is highly dependent on the region and the environment. Anopheles gambiae (sensu stricto) and An. funestus are the most common species of Anopheles in Ghana, followed by An. coluzzii, all found throughout the entire country. Two other species, An. melas and An. rufipes, are restricted to the southern and the northernmost parts of Ghana, respectively $[1,2]$.

\footnotetext{
*Correspondence: mamiboatemah@yahoo.co.uk

${ }^{1}$ Kumasi Centre for Collaborative Research (KCCR), College of Health Sciences, Kumasi, Ghana

${ }^{2}$ Department of Theoretical and Applied Biology, College of Science, Kwame Nkrumah University of Science and Technology (KNUST), Kumasi, Ghana Full list of author information is available at the end of the article
}

Since indoor residual spraying (IRS) and long-lasting insecticidal nets (LLINs) are the main malaria vector control measures used in several sub-Saharan countries, the World Health Organization (WHO) has approved certain classes of insecticides to be used in their formulation namely, pyrethroids for both LLINs and IRS and organophosphates, carbamates and organochlorides for IRS only $[3,4]$.

Organophosphate and carbamate insecticides act irreversibly on inactivating the enzyme acetylcholinesterase which is essential for nerve function in mosquitoes [5]. The insecticidal effect of pyrethroids and DDT is due to insecticide binding to the sodium channel, modifying its gating properties, and keeping it open for a relatively longer period. Modifications in the sodium channel structure in the form of point mutations or substitutions 
as a result of single nucleotide polymorphisms confer insensitivity to DDT and pyrethroids. Although several chemicals are in use in urban areas, pyrethroids are the most widely selected and preferred class of insecticides for vector control because of their effectiveness, low toxicity to humans and high mosquito repellent properties [6]. The vectors of malaria are becoming increasingly resistant to many classes of insecticides in various parts of Ghana [7]. The upsurge in physiological insecticide resistance has multiple and interacting underlying mechanisms include metabolic detoxification, reduced insecticide infiltration and behavioural avoidance as well as cross-resistance [8].

The tendency for cross-resistance with respect to different classes of insecticides arises especially for groups sharing the same mode of action. The occurrence of cross-resistance will restrict the choice of alternative chemicals in situations where resistance has been detected. In view of the existence of cross-resistance, the WHO launched the Global Plan for Insecticide Resistance Management in Malaria Vectors (GPIRM) in May 2012, which is explicit on the need for closer monitoring of insecticide resistance, especially to pyrethroids [9].

There are several calls for the establishment of effective reporting mechanisms to ensure that information on species and insecticide resistance distribution are collected, assembled and fed back into the decision-making process $[10,11]$. Vector control interventions will, therefore, be more responsive to the local situation leading to improved efficiency and effectiveness. As a result, there have been a number of published data from studies conducted mostly in small communities of Ghana [7, 12, 13]. Kumasi is a fast growing and urbanising city in Ghana and as expected there is high demand on food supply leading to exponential growth of irrigated agriculture in this urban setting. While the creation of irrigated farmlands serve as larval sites for the proliferation of An. gambiae (s.l.), there is a lack of data on the population of vectors as well as their resistance to the use of insecticides in an urban setting such as Kumasi. We therefore studied the use of major classes of insecticides recommended by the WHO in relation to different species of malaria vectors in this mosquito population.

\section{Methods}

\section{Study area}

The study was carried out in Kumasi Metropolis, Ghana. Kumasi lies in the southern belt of Ghana and covers 25,415 ha of the total land area of the country. Average annual rainfall is $625 \mathrm{~m}$ with peaks of 214.3 and $165.2 \mathrm{~mm}$ in June and September, respectively. This region lies in the forest zone where malaria transmission is intense and perennial. The level of disease transmission is high throughout the year because favourable environment exist [14].
The study site, Asokwa submetropolis in Kumasi Metropolis is the most populated of the five health submetropolis with a population of 495,375 (Kumasi Maps and Population, unpublished data). The submetropolis is made up of 26 communities and has the highest number of major irrigated vegetable farms in the metropolis. The vegetables cultivated on these irrigated farms include cabbage, green pepper, pepper, carrot, lettuce, spring onions, spinach, garden eggs, and cauliflower [15]. These fields represent highly productive larval sites and are found throughout Kumasi $[16,17]$.

\section{Mosquito sampling}

Anopheles larvae and pupae were sampled from major open-spaced irrigated vegetable farms in the submetropolis and reared to adults in an insectary. The larvae were reared under standard conditions at $26-28{ }^{\circ} \mathrm{C}$, $12: 12 \mathrm{~h}$ photocycle and $70-80 \%$ relative humidity in the insectary. The adults were fed on 5\% sugar solution soaked in cotton wool. Three to five day-old non-blood fed female adult Anopheles mosquitoes from each six major larval sites were then pooled and observed for an hour to ensure their fitness for insecticide susceptibility testing. Anopheles specimens were declared fit when they flew with all parts of their body intact. Any Anopheles that died, became immobile and/or lost any part of its appendages was declared unfit and discarded according to WHO requirement [18].

\section{Insecticide susceptibility assays}

Insecticide susceptibility assays were performed on the wild larvae reared to adult in the laboratory using the standard WHO susceptibility test protocol and mortality rates calculated after $24 \mathrm{~h}$ [9]. A susceptible strain of $A n$. gambiae (Kisumu) was used as reference strain for the bioassays. Insecticide-impregnated test papers with the WHO diagnostic dosages were supplied by the Universiti Sains Malaysia, Penang. Test papers were impregnated with pyrethroids $(0.05 \%$ deltamethrin, $0.15 \%$ cyfluthrin, $0.05 \%$ lambda-cyhalothrin, and $0.75 \%$ permethrin); carbamates ( $0.1 \%$ propoxur and $0.1 \%$ bendiocarb); organophosphates (5.0\% malathion and $0.25 \%$ pirimiphos-methyl) and organochlorides (4.0\% dieldrin and $4.0 \%$ dichlorodiphenyltrichloroethane, DDT). For each insecticide, five tubes were prepared plus a tube for control. Twenty to twenty-five (20-25) randomly selected female Anopheles were used at $26-28{ }^{\circ} \mathrm{C}$ and $70-80 \%$ relative humidity.

The knockdown effect of insecticides on the mosquitoes were observed for every $5 \mathrm{~min}$ for the first $20 \mathrm{~min}$ and then every $10 \mathrm{~min}$ till the total time was an hour to obtain the knockdown effect (KD). Thereafter, mosquitoes were observed for $24 \mathrm{~h}$ with a piece of cotton soaked with sugar solution $(5 \%)$ on the grille of the cork to feed the 
mosquitoes. The percentage of female Anopheles mosquitoes that died after the $24 \mathrm{~h}$ were recorded as the mortality rate for each insecticide all in conformity to WHO standards.

\section{Identification of Anopheles spp.}

DNA was extracted from the legs and wings of dead and surviving Anopheles exposed to pyrethroids and organochlorides from WHO tube susceptibility test. The cetyl trimethyl ammonium bromide (CTAB) protocol was used [19]. Thereafter, downstream PCR for species identification of An. coluzzii, An. gambiae (s.s.) and An. arabiensis was performed as described previously [20].

\section{Resistance marker genotyping}

To find out if target-site insensitivity were responsible for resistance in Anopheles after the WHO tube assay was performed, PCR genotyping of $k d r$ and ace-1 were carried out.

The allele specific PCR procedure for $k d r$ genotyping was intended to detect the West African $k d r$ allele, L1014F, using the protocol and primer sequence of Martinez-Torres et al. [21]. The L1014F was the only gene mutation analysed because it is the commonest in West Africa whereas the L1014S mutation is confined in eastern Africa [20]. Allele specific (AS) PCR (a conventional PCR) was chosen for $k d r$ mutation detection in Anopheles mosquitoes although real time (RT) PCR is the most sensitive and specific assay to use. This PCR was however chosen on the basis of its relative lower cost and reports of small number of failed reactions and incorrect scores [22]. The primers AgD1 (5'-ATA GAT TCC CCG ACC ATG-3') and AgD3 (5'-AAT TTG CAT TAC TTA CGA CA-3') amplified the resistant allele yielding $195 \mathrm{bp}$ fragments. The susceptible allele was assayed using primers AgD2 (5' -AGA CAA GGA TGA TGA ACC-3') and AgD4 (5'-CTG TAG TGA TAG GAA ATT TA-3'), which amplified a 137 bp fragment. The primer set AgD1 and AgD2 amplified a common fragment of $293 \mathrm{bp}$ for control. During amplification, denaturation was set at $94{ }^{\circ} \mathrm{C}$ for 3 min followed by annealing; 35 cycles $\left(94{ }^{\circ} \mathrm{C}\right.$ for $30 \mathrm{~s}, 55{ }^{\circ} \mathrm{C}$ for $30 \mathrm{~s}$, $72{ }^{\circ} \mathrm{C}$ for $10 \mathrm{~s}$ ). Extension was set at $72{ }^{\circ} \mathrm{C}$ for $5 \mathrm{~min}$.

Similarly, PCR to detect ace-1 G119S mutation as described by Weill et al. [23] was carried out with the primers, Ex3Agdir (5'-GAT CGT GGA CAC CGT GTT CG-3') and Ex3Agrev (5'-AGG ATG GCC CGC TGG AAC AG-3'), which amplified a fragment of $541 \mathrm{bp}$. An initial denaturation for $3 \mathrm{~min}$ at $94{ }^{\circ} \mathrm{C}$ was run, followed by annealing, 35 cycles $\left(94{ }^{\circ} \mathrm{C}\right.$ for $30 \mathrm{~s}, 62{ }^{\circ} \mathrm{C}$ for $30 \mathrm{~s}$, $72{ }^{\circ} \mathrm{C}$ for $20 \mathrm{~s}$ ) and a final extension for $5 \mathrm{~min}$ at $72{ }^{\circ} \mathrm{C}$. The PCR products $(4 \mu \mathrm{l})$ were then digested with $\mathrm{Alu} \mathrm{I}$ restriction enzyme according to the manufacturer instruction. The digestion was to produce a $403 \mathrm{bp}$ fragment for susceptible homozygous mosquitoes (SS), and two fragments of $253 \mathrm{bp}$ and $150 \mathrm{bp}$ for homozygous resistant (RR). Heterozygous individuals (RS) show a combination of sensitive and homozygous resistant bands.

\section{Data management}

All data were entered into Microsoft Excel 2010, doublechecked to correct for errors and then exported to GraphPad Prism 5 for statistical analysis. In the case of a Gaussian distribution data, determined using the D'Agostino \& Pearson omnibus normality test, one sample $t$-test and the parametric unpaired $t$-test were used while Mann-Whitney nonparametric test was used for data with a non-Gaussian distribution to estimate the differences in resistance between the different Anopheles species and insecticides and also against the Kisumu susceptible strain. Alpha level of 5\% was accepted as statistically significant. The susceptibility levels of the mosquitoes were evaluated on the basis of the WHO criteria of test mortality [24].

\section{Results \\ WHO insecticide susceptibility tube assay}

All 1,197 Anopheles gambiae Kisumu strain were susceptible $(98-100 \%)$ to the 10 tested insecticides which also presented with significant difference to the wild strain used in determining malaria vector insecticide resistance $\left(t_{(18)}=5.74, P<0.0001\right)$. Bioassay results for these wild Anopheles gambiae (s.l.) from the Asokwa submetropolis was indicative of resistance to carbamates (38-56\%), organochlorides (38-46\%) and the pyrethroids (15-47\%) but susceptible to the organophosphates (98$100 \%)$ (Table 1). There was a statistically significant difference in mortality of the Anopheles gambiae (s.l.) to each insecticide tested $\left(t_{(9)}=4.94, P=0.0008\right.$ ). For each insecticide, the rate of mortality in the controls used were less than $5 \%$, therefore no corrections using the Abbot's formula were required.

\section{Knockdown effect of insecticides}

As shown in Fig. 1, the organophosphates that also had the highest rate of mortality after $24 \mathrm{~h}$ had the highest knockdown (KD) (57\%) after $60 \mathrm{~min}$ of exposure to the insecticide, followed by the carbamates $(41 \%$ at $60 \mathrm{~min})$. The pyrethroids had the least knockdown effect of $25 \%$ at $60 \mathrm{~min}$.

\section{Molecular identification of Anopheles gambiae (s.l.) and characterization of resistance genes $k d r$ and ace- 1}

Of the 1,069 female Anopheles mosquitoes used for the phenotypic detection of insecticide resistance, 619 were used for molecular Anopheles identification; of these, the majority (87\%) were An. gambiae (s.s.) and the remaining $13 \%$ were An. coluzzii. Among the An. coluzzii and the 
Table 1 Resistance status of Anopheles gambiae (s.l.) strains collected at Asokwa submetropolis and Kisumu laboratory strains to the four main classes of insecticides recommended by WHO

\begin{tabular}{|c|c|c|c|c|c|c|c|c|}
\hline Insecticide & Strain & $N$ & Dead $(n)$ & Survived $(n)$ & Mortality (\%) & Resistance (\%) & $95 \% \mathrm{Cl}$ & Susceptibility status \\
\hline \multicolumn{9}{|l|}{ Organophosphates } \\
\hline \multirow[t]{2}{*}{ Malathion (5\%) } & Asokwa submetropolis & 125 & 123 & 2 & 98 & 2 & $0.96-1.01$ & $S$ \\
\hline & Kisumu & 124 & 124 & 0 & 100 & 0 & - & S \\
\hline \multirow{2}{*}{$\begin{array}{l}\text { Pirimiphos-methyl } \\
(0.25 \%)\end{array}$} & Asokwa submetropolis & 107 & 107 & 0 & 100 & 0 & - & S \\
\hline & Kisumu & 125 & 125 & 0 & 100 & 0 & - & S \\
\hline \multicolumn{9}{|l|}{ Carbamates } \\
\hline \multirow[t]{2}{*}{ Propoxur (0.1\%) } & Asokwa submetropolis & 119 & 67 & 52 & 56 & 44 & $0.47-0.65$ & $\mathrm{R}$ \\
\hline & Kisumu & 120 & 119 & 1 & 99 & 1 & $0.98-1.01$ & $S$ \\
\hline \multirow[t]{2}{*}{ Bendiocarb (0.1\%) } & Asokwa submetropolis & 99 & 38 & 61 & 38 & 62 & $0.29-0.48$ & $\mathrm{R}$ \\
\hline & Kisumu & 122 & 120 & 2 & 98 & 2 & $0.96-1.01$ & $\mathrm{~S}$ \\
\hline \multicolumn{9}{|l|}{ Pyrethoids } \\
\hline \multirow[t]{2}{*}{ Cyfluthrin (0.15\%) } & Asokwa submetropolis & 109 & 34 & 75 & 31 & 69 & $0.22-0.40$ & $\mathrm{R}$ \\
\hline & Kisumu & 125 & 124 & 1 & 99 & 1 & $0.98-1.01$ & $S$ \\
\hline \multirow[t]{2}{*}{ Deltamethrin (0.05\%) } & Asokwa submetropolis & 102 & 48 & 54 & 47 & 53 & & $\mathrm{R}$ \\
\hline & Kisumu & 105 & 105 & 0 & 100 & 0 & - & S \\
\hline \multirow{2}{*}{$\begin{array}{l}\text { Lambda-cyhalothrin } \\
(0.05 \%)\end{array}$} & Asokwa submetropolis & 104 & 16 & 88 & 15 & 85 & $0.08-0.22$ & $\mathrm{R}$ \\
\hline & Kisumu & 107 & 106 & 1 & 99 & 1 & $0.97-1.01$ & $S$ \\
\hline \multirow[t]{2}{*}{ Permethrin (0.75\%) } & Asokwa submetropolis & 101 & 26 & 75 & 26 & 74 & $0.17-0.34$ & $\mathrm{R}$ \\
\hline & Kisumu & 124 & 124 & 0 & 100 & 0 & - & $S$ \\
\hline \multicolumn{9}{|l|}{ Organochorides } \\
\hline \multirow[t]{2}{*}{ DDT (4\%) } & Asokwa submetropolis & 108 & 41 & 67 & 38 & 62 & $0.29-0.47$ & $\mathrm{R}$ \\
\hline & Kisumu & 121 & 121 & 0 & 100 & 0 & - & S \\
\hline \multirow[t]{2}{*}{ Dieldrin (4\%) } & Asokwa submetropolis & 95 & 44 & 51 & 46 & 54 & $0.36-0.56$ & $\mathrm{R}$ \\
\hline & Kisumu & 124 & 123 & 1 & 99 & 1 & $0.98-1.01$ & $\mathrm{~S}$ \\
\hline
\end{tabular}

Abbreviations: $N$ total number, $R$ resistant, $S$ susceptible, $C l$ confidence interval, - not determined

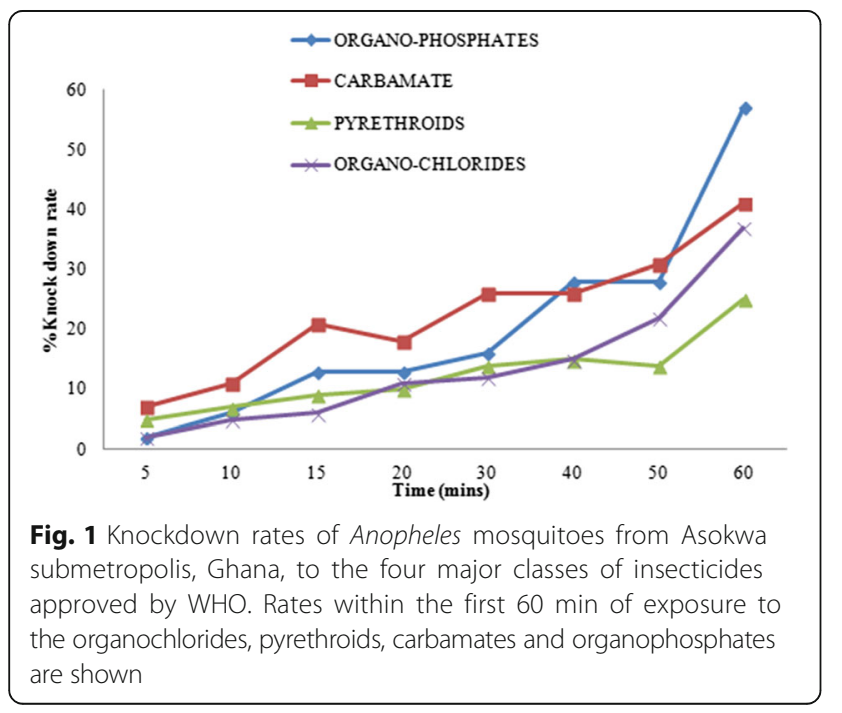

An. gambiae (s.s.) identified, $k d r$ mutation was detected at a frequency of 91 and $61 \%$, respectively. This difference in $k d r$ mutant gene detection between the different species was highly significant $\left(U_{(5)}=0, Z=2.802, P=0.002\right.$ (Table 2). Over a half of An. gambiae (s.l.) that survived the WHO tube assay test had $k d r$ mutant genes but far lower proportions were recorded for those that died. All pyrethroid insecticides, of which permethrin was the highest, that An. gambiae (s.l.) survived during the tube assay test recorded with the highest $k d r$ gene mutation (85-94\%). DDT of the organochlorides reporting with the

Table $2 \mathrm{kdr}$ resistance in An. gambiae (s.s.) and An. coluzzii from both dead and alive mosquitoes during the WHO tube assay test

\begin{tabular}{llll}
\hline & $k d r$-resistant $n(\%)$ & $k d r$-sensitive $n(\%)$ & Total $n(\%)$ \\
\hline An. gambiae (s.5.) & $329(61)$ & $208(39)$ & $537(87)$ \\
An. coluzzii & $75(91)$ & $7(9)$ & $82(13)$ \\
Total & $404(65)$ & $215(35)$ & $619(100)$ \\
\hline
\end{tabular}


least An. gambiae (s.l.) $k d r$ for those that survived however had the highest $k d r$ mutant gene representation for those that died (Table 3). Ace-1 mutation on the other hand was not detected among the female Anopheles mosquitoes subjected to organophosphates and carbamates.

\section{Discussion}

In Kumasi, An. gambiae (s.l.) was seen to be widespread with majority (87\%) being An. gambiae (s.s.), in agreement with similar studies in the country $[7,25,26]$. The lower proportion of An. coluzzii was not surprising since this species is mostly linked to bigger and more permanent larval sites found in rice paddy fields, whereas $A n$. gambiae (s.s.) are normally sampled from temporary, rain-filled larval sites in vegetable growing areas [2729]. Klinkinberg et al. [28] who worked on a comparable urban setting in the country also recorded similar $A n$. gambiae (s.s.) and An. coluzzii proportions among adult mosquito population. Interestingly, Afrane et al. [17] found no An. coluzzii while sampling in Kumasi over a decade ago. Bearing in mind that the sampling carried out by Afrane et al. was at the same location as this study, it depicts a gradual emergence of An. coluzzii population over the years in the said area. This probably is due to the advent of copious dug out wells for all year round irrigation purposes which are thus more permanent hence an attractant for this specie complex. This said, subsequent studies need to be carried out to affirm or otherwise this observation.

Only An. coluzzii contributed to malaria transmission with a high level of anthropomorphism and EIR in a study carried out in Ghana [30]. This means that the appearance of $A n$. coluzzii has a significant implication for malaria transmission. This baseline results however require substantiation on a larger sampling scale and during different and extended periods in the year so as to utilize such localized malaria entomological data, which relates to the behaviour of the vector. This will definitely assist in the planning and implementation of more focused malaria vector control programmes. Especially in the event of such high Leu-Phe $k d r$ mutation, which is the main mechanism of insecticide resistance in malaria vectors to pyrethroids in West Africa noted among this population of An. coluzzii (91\%). This elevated level of $k d r$ mutation in $A n$. coluzzii has been in a steady rise since the early 2000's after which there was a 15-fold increase by 2011 [1,31]. Before the year 2000, Chandre et al. [32] associated $k d r$ mutation with An. gambiae (s.s.) only but not An. coluzzii. The reason for this possible crossover in $k d r$ frequencies to $A n$. coluzzii is conceivably through introgression from the An. gambiae (s.s.) [33]. However, further work needs to be carried out to ascertain whether this introgression incidence is what is actually pertaining in the setting of this study.

While ace-1 gene mutation was absent contrary to other reports in some sub-Saharan countries [34, 35], $k d r$ gene mutation was detected at $65 \%$ in $A n$. gambiae (s.l.). The degree of $k d r$ mutation observed was as high as reported in other parts of Ghana and West Africa [31, 36, 37].

The development of phenotypic and genotypic resistance to WHO-approved insecticides by Anopheles mosquitoes has been linked to agriculture [4, 27]. It is estimated that $87 \%$ vegetable farmers in Ghana principally rely on insecticides for pest control $[38,39]$ due to their effectiveness and rapidity in curative action [40]. However, during insecticide application, chemicals seep into larval sites. Mosquito larvae present are thus continuously exposed. Exposure to these insecticides could lead to an increase in resistance in mosquitoes [5]. Alarmingly, pyrethroids, which are used in ITNs, are the most widely used insecticides by farmers because of their photostability, enhanced insecticidal activity and relatively low toxicity as compared to the others [41]. Unfortunately, application of insecticides in agriculture is not regulated in Ghana. They are therefore used

Table $3 \mathrm{kdr}$ resistance of An. gambiae (s.s.) and An. coluzzii to organochlorides and pyrethroids during the WHO tube assay test segregated into dead and alive mosquitoes

\begin{tabular}{|c|c|c|c|c|c|c|c|c|c|}
\hline \multirow[t]{2}{*}{ Insecticide } & \multicolumn{3}{|c|}{$k d r$-resistant (alive) $n(\%)$} & \multicolumn{3}{|c|}{ kdr-resistant (dead) n (\%) } & \multicolumn{3}{|c|}{ kdr-sensitive $n(\%)$} \\
\hline & $\begin{array}{l}\text { An. } \\
\text { gambiae }\end{array}$ & $\begin{array}{l}\text { An. } \\
\text { coluzzii }\end{array}$ & Total & $\begin{array}{l}\text { An. } \\
\text { gambiae }\end{array}$ & $\begin{array}{l}\text { An. } \\
\text { coluzzii }\end{array}$ & Total & $\begin{array}{l}\text { An. } \\
\text { gambiae }\end{array}$ & $\begin{array}{l}\text { An. } \\
\text { coluzzii }\end{array}$ & Total \\
\hline \multicolumn{10}{|l|}{ Organochorides } \\
\hline DDT (4\%) & $53(83)$ & $13(17)$ & $66(65)$ & $19(100)$ & $0(0)$ & $19(35)$ & $21(100)$ & $2(0)$ & $23(25)$ \\
\hline Dieldrin (4\%) & $37(65)$ & $10(35)$ & $47(83)$ & $12(100)$ & $0(0)$ & $12(17)$ & $32(60)$ & $4(40)$ & $36(10)$ \\
\hline \multicolumn{10}{|l|}{ Pyrethoids } \\
\hline Deltametrin (0.05\%) & $45(88)$ & $0(12)$ & $45(85)$ & $9(82)$ & $2(18)$ & $11(15)$ & $45(100)$ & $1(0)$ & $46(24)$ \\
\hline Permathrin (0.75\%) & $28(67)$ & $24(33)$ & $52(94)$ & $5(100)$ & $0(0)$ & $5(6)$ & $44(100)$ & $0(0)$ & $44(25)$ \\
\hline Cyfluthrin (0.15\%) & $49(86)$ & $26(14)$ & $75(93)$ & $9(100)$ & $0(0)$ & $9(7)$ & $25(100)$ & $0(0)$ & $25(17)$ \\
\hline Lambda-cyhalothrin (0.05\%) & $58(86)$ & $0(14)$ & $58(93)$ & $5(100)$ & $0(0)$ & $5(7)$ & $41(100)$ & $0(0)$ & $41(17)$ \\
\hline
\end{tabular}


extensively, indiscriminately and even in overdose [25], explaining the pronounced resistance effect on vector mosquitoes as seen here. As a matter of urgency, application of insecticides by farmers should be well monitored by employing locals who will patrol and educate farmers on alternative pest control tools.

On a large scale, IRS and LLINs, the main malaria vector control tools in Ghana have significant variations with respect to regional coverage. LLINs are the focal malaria control tool in Ghana, increasing from $2.2 \%$ in 2003 to $48.9 \%$ in 2011 [42-44]. All of the ten regions in the country have been covered with the 'door to door' campaign that was implemented from 2010 to 2012 having an impressive coverage of $96.7 \%$ [44]. IRS however was designed initially to focus on 40 selected districts with two rounds of application based on the burden and technical practicability. As at the end of 2013, the plan was modified due to Global Fund allocation requiring a reduction of the districts to 12 of which all have been covered. The main facilitators of IRS in Ghana are AngloGold Ashanti Malaria Control (AGAMal) and the United States Agency for International DevelopmentPresident's Malaria Initiative (USAID-PMI) [45, 46]. In addition to IRS and LLINs, there are also household use of insecticide consumer products such as aerosol, mosquito coils, liquid vaporizers and repellents [47, 48]. In all these, the most common chemical used is a pyrethroid. This may be a contributory factor to the build-up of insecticide resistance in local mosquito populations. The continuous exposure adds up to mosquitoes becoming strongly resistant to pyrethroids as well as other commonly used insecticides [49].

In Ghana organophosphates and carbamates are used interchangeably in IRS and this may have contributed to an extent the high resistance of Anopheles gambiae (s.l.) to these insecticides. High resistance to carbamates was observed notwithstanding cross-resistance with organophosphates, to which Anopheles gambiae (s.l.) were highly susceptible. This was as a result of reported complexity of insecticide resistance mechanism in mosquitoes of which Pedra et al. [50] indicated that wider range of genes are likely to be involved than the already stipulated genes. In addition to the target site-insensitivity as a result of point mutation or structural modification, increased metabolic detoxification of insecticides in mosquitoes is the most implicated mechanism [51]. Hence resistance observed to carbamates could be a result of metabolic detoxification of this insecticide by Anopheles spp. There is another school of thought that suggests that carbamates in contrast to organophosphates have reversible action on cholinesterase. The enzymatic activity is restored within a short while as carbamates lose their potential to restrain anticholinesterase thus rendering them less effective [52].
Effective insecticide resistance management is highly essential in preventing resistance, regain susceptibility or delay the development of resistance in mosquitoes to support and improve public health. An all-inclusive integrated vector control strategy including biological, chemical, physical, molecular, environmental and educational aspects targeting the various stages of the vectors, is long overdue and should be implemented in all malaria endemic countries as soon as possible. Ghana as a nation has adapted an insecticide resistance management plan, which was informed based on a nationwide survey, conducted to identify gaps in insecticide resistance data in the country. The plan comprises of the setting up of sentinel sites for the routine monitoring of insecticide resistance by renowned research institutions in the country. This exercise is thus ongoing throughout the nation, which will inform the next stage of action to be taken [45].

Our study had some limitations. Even though sampling was from the most populous region of Kumasi, mosquito larvae were from farms and not households. It is possible that the sampled population may not reflect exactly that which pertains all over Ashanti region. Therefore one ought to interpret these results with caution. That notwithstanding, several studies have revealed similar Anopheles population comparable to findings in this study.

\section{Conclusions}

Since the high use of insecticides in irrigated farms in urban areas are probably a contributory factor to the development of resistance in the malaria vector, there should be continuous monitoring of use. The high coverage of LLINs and other insecticide malaria control measures in urban areas may strongly select for $k d r$ mutations hence the high prevalence in An coluzzii (91\%) and An. gambiae (s.s.) (61\%). This study reveals that $A n$. gambiae (s.l.) from Asokwa submetropolis in the Ashanti Region are resistant to all classes of insecticides except for organophosphates. Pirimiphose-methyl $(0.25 \%)$ belonging to the organophosphates is the most effective insecticide against malaria vectors. Pyrethroids, the most widely used insecticide in ITNs and IRS had the highest level of resistance in the population of mosquito vectors. Our study therefore advocates the use of organophosphates in IRS as a malaria control tool boost to LLINs in these areas while effective insecticide resistance management plan is adapted and strictly adhered to.

\footnotetext{
Abbreviations

ace-1: Acetylcholinesterase; AS: Allele-specific; CHRPE: Committee on human research publication and ethics; CTAB: Cetyl trimethyl ammonium bromide; DDT: Dichlorodiphenyltrichloroethane; IRS: Indoor residual spraying;

ITN: Insecticide-treated nets; KCCR: Kumasi centre for collaborative research into tropical medicine; KD: Knockdown effect; kdr: knockdown resistance;

KNUST: Kwame Nkrumah University of Science and Technology; LLINs: Long-lasting insecticide nets; PCR: Polymerase chain reaction; WHO: World Health Organisation
} 


\section{Acknowledgments}

We are indebted to Prof. Roch K. Dabire for providing us with laboratory space and reagents. We are grateful to EOD working group, Richard Larbi, Victoria Dede Teye, Stephen Abankwa Kwarteng, Kofi Konadu Boateng, Lucy Bingham, Anthony Affum-Adjei Awuah, Portia Boakye Okyere, Aliyu Abdul Wahab and Gabriel Otuo Acheampong for assisting in larval sampling, data collection and analysis and laboratory analysis.

Finally, the study team is grateful to all vegetable farmers within the study area.

\section{Funding}

This study was funded by the EOD (Ellis Owusu-Dabo) research working group at Kumasi Centre for Collaborative Research. The design of the study, analysis, and interpretation of data and writing the manuscript were sole carried out by the authors and does not reflect those of the funding body.

\section{Availability of data and materials}

All data generated or analysed during this study are included in the article.

\section{Authors' contributions}

SBA acquisition of field and laboratory data, interpretation of data, drafting article; AAA critical supervision and revision of article for important intellectual content; OMA critical supervision and revision of article for important intellectual content; SDD acquisition of laboratory data; PAK acquisition of field and laboratory data; EOD critical supervision and revision of article for important intellectual content; KOD critical supervision and revision of article for important intellectual content. All authors read and approved the final version of the manuscript.

\section{Competing interests}

The authors declare that they have no competing interests.

\section{Consent for publication}

Not applicable.

\section{Ethics approval and consent to participate}

Ethical clearance was obtained from the Kwame Nkrumah University of Science and Technology (KNUST), Committee on Human Research Publication and Ethics (CHRPE), Ref: CHRPE/AP/343/14.

\section{Author details}

${ }^{1}$ Kumasi Centre for Collaborative Research (KCCR), College of Health Sciences, Kumasi, Ghana. ${ }^{2}$ Department of Theoretical and Applied Biology, College of Science, Kwame Nkrumah University of Science and Technology (KNUST), Kumasi, Ghana. ${ }^{3}$ Bernhard-Nocht Institute for Tropical Medicine (BNITM), Hamburg, Germany. ${ }^{4}$ Institut de Recherche en Sciences de la Santé (IRSS), Ouagadougou, Burkina Faso. ${ }^{5}$ School of Public Health, College of Health Sciences, KNUST, Kumasi, Ghana.

\section{Received: 8 April 2016 Accepted: 1 December 2016}

\section{Published online: 07 December 2016}

\section{References}

1. Yawson A, McCall P, Wilson M, Donnelly M. Species abundance and insecticide resistance of Anopheles gambiae in selected areas of Ghana and Burkina Faso. Med Vet Entomol. 2004:18:372-7.

2. Appawu M, Baffoe-Wilmot A, Afari E, Dunyo S, Koram K, Nkrumah F. Malaria vector studies in two ecological zones in southern Ghana. Afr Entomol. 2000;9:59-65.

3. World Health Organization. Recommended insecticides for indoor residual spraying against malaria vectors. Geneva: WHO; 2013.

4. World Health Organization. Recommended long-lasting insecticidal nets. Geneva: WHO; 2014

5. Čolović MB, Krstić DZ, Lazarević-Pašti TD, Bondžić AM, Vasić VM. Acetylcholinesterase inhibitors: pharmacology and toxicology. Curr Neuropharmacol. 2013;11:315-35.

6. Diabate A, Baldet T, Chandre F, Akoobeto M, Guiguemde TR, Darriet F, et al. The role of agricultural use of insecticides in resistance to pyrethroids in Anopheles gambiae sl in Burkina Faso. Am J Trop Med Hyg. 2002;67:617-22.

7. Hunt R, Fuseini G, Knowles S, Stiles-Ocran J, Verster R, Kaiser M, et al. Insecticide resistance in malaria vector mosquitoes at four localities in Ghana, West Africa. Parasit Vectors. 2011;4:107.
8. Ketterman AJ, Saisawang C, Wongsantichon J. Insect glutathione transferases. Drug Metab Rev. 2011:43:253-65.

9. World Health Organization. Test procedures for insecticide resistance monitoring in malaria vector mosquitoes. Geneva: WHO; 2013.

10. Hay SI, Rogers DJ, Toomer JF, Snow RW. Annual Plasmodium falciparum entomological inoculation rates (EIR) across Africa: literature survey, internet access and review. Trans R Soc Trop Med Hyg. 2000;94:113-27.

11. Kabula B, Derua YA, Tungu PK, Massue DJ, Sambu E, Mosha FW, Kisinza WN. Malaria entomological profile in Tanzania from 1950 to 2010: a review of mosquito distribution, vectorial capacity and insecticide resistance. Tanzan J Health Res. 2011;13:319-31.

12. Mitchell SN, Stevenson BJ, Müller P, Wilding CS, Egyir-Yawson A, Field SG, et al. Identification and validation of a gene causing cross-resistance between insecticide classes in Anopheles gambiae from Ghana. Proc Natl Acad Sci. 2012;109:6147-52

13. Okoye PN, Brooke BD, Koekemoer LL, Hunt RH, Coetzee M. Characterisation of DDT, pyrethroid and carbamate resistance in Anopheles funestus from Obuasi, Ghana. Trans R Soc Trop Med Hyg. 2008;102:591-8.

14. de Souza D, Kelly-Hope L, Lawson B, Wilson M, Boakye D. Environmental factors associated with the distribution of Anopheles gambiae ss in Ghana; an important vector of lymphatic filariasis and malaria. PLoS One. 2010; doi:10.1371/jounal.pone.0009927.

15. Drechsel P, Keraita B. Irrigated urban vegetable production in Ghana: characteristics, benefits and risk mitigation. 2nd ed. IWMI: Colombo; 2014.

16. Nartey R, Owusu-Dabo E, Kruppa T, Baffour-Awuah S, Annan A, Oppong S, et al. Use of Bacillus thuringiensis var. israelensis as a viable option in an integrated malaria vector control programme in the Kumasi Metropolis, Ghana. Parasit Vectors. 2013;6:116.

17. Afrane YA, Klinkenberg E, Drechsel P, Owusu-Daaku K, Garms R, Kruppa T. Does irrigated urban agriculture influence the transmission of malaria in the city of Kumasi, Ghana? Acta Trop. 2004;89:125-34.

18. World Health Organization. Test procedures for insecticide resistance monitoring, bio-efficacy and persistence of insecticides on treated surfaces. Geneva: WHO: 1998.

19. Barik SK, Hazra RK, Prusty MR, Rath A, Kar SK. A simple, rapid and very efficient protocol for DNA isolation from mosquito species. Protoc Exch. 2013. doi:10.1038/protex.007.

20. Santolamazza F, Mancini E, Simard F, Qi Y, Tu Z, della Torre A. Insertion polymorphisms of SINE200 retrotransposons within speciation islands of Anopheles gambiae molecular forms. Malar J. 2008;7:163.

21. Martinez-Torres D, Chandre F, Williamson M, Darriet F, Berge J, Devonshire A, et al. Molecular characterization of pyrethroid knockdown resistance (kdr) in the major malaria vector Anopheles gambiae s.s. Insect Mol Biol. 1998;7:179-84.

22. Bass C, Nikou D, Donnelly MJ, Williamson MS, Ranson H, Ball A, Vontas J, Field LM. Detection of knockdown resistance ( $k d r$ ) mutations in Anopheles gambiae: a comparison of two new high-throughput assays with existing methods. Malar J. 2007:6:111.

23. Weill M, Lutfalla G, Mogensen K, Chandre F, Berthomieu A, Berticat C, et al. Comparative genomics: Insecticide resistance in mosquito vectors. Nature. 2003:423:136-7.

24. World Health Organization. Test procedures for insecticide monitoring in malaria vectors, bioefficacy and persistence of insecticides on treated surfaces. Geneva: WHO/CDS/CDC/MAL/98.12; 1998.

25. Coetzee M, Van Wyk P, Booman M, Koekemoer L, Hunt R. Entomologie médicale. Bull Soc Pathol Exot. 2006:99:400-3.

26. Badu K, Brenya RC, Timmann C, Garms R, Kruppa TF. Malaria transmission intensity and dynamics of clinical malaria incidence in a mountainous forest region of Ghana. MWJ. 2013;4:14.

27. Gimonneau G, Pombi M, Choisy M, Morand S, Dabiré RK, Simard F. Larval habitat segregation between the molecular forms of the mosquito Anopheles gambiae in a rice field area of Burkina Faso, West Africa. Med Vet Entomol. 2012;26:9-17.

28. Klinkenberg E, McCall P, Wilson MD, Amerasinghe FP, Donnelly MJ. Impact of urban agriculture on malaria vectors in Accra, Ghana. Malar J. 2008;7:1-9.

29. Dabiré KR, Diabaté A, Djogbenou L, Ouari A, N'Guessan R, Ouédraogo J-B, et al. Dynamics of multiple insecticide resistance in the malaria vector Anopheles gambiae in a rice growing area in southwestern Burkina Faso. Malar J. 2008;7:188.

30. Tchouassi DP, Quakyi IA, Addison EA, Bosompem KM, Wilson MD, Appawu $M A$, et al. Characterization of malaria transmission by vector populations for improved interventions during the dry season in the Kpone-on-Sea area of coastal Ghana. Parasit Vectors. 2012;5:1. 
31. Kabula Bl, Attah PK, Wilson MD, Boakye DA. Characterization of Anopheles gambiae s.l. and insecticide resistance profile relative to physicochemical properties of breeding habitats within Accra Metropolis, Ghana. Tanzan J Health Res. 2011;13:163-87.

32. Chandre F, Manguin S, Brengues C, Dossou YJ, Darriet F, Diabate A, et al. Current distribution of a pyrethroid resistance gene $(\mathrm{kdr})$ in Anopheles gambiae complex from west Africa and further evidence for reproductive isolation of the Mopti form. Parassit. 1999;41:319-22.

33. Weill M, Chandre F, Brengues C, Manguin S, Akogbeto M, Pasteur N, et al. The kdr mutation occurs in the Mopti form of Anopheles gambiae s.s. through introgression. Insect Mol Biol. 2000;9:451-5.

34. Essandoh J, Yawson AE, Weetman D. Acetylcholinesterase (ace-1) target site mutation $119 \mathrm{~S}$ is strongly diagnostic of carbamate and organophosphate resistance in Anopheles gambiae s.s. and Anopheles coluzzii across southern Ghana. Malar J. 2013:12:404.

35. Djogbénou L, Dabiré R, Diabaté A, Kengne $P$, Akogbéto M, Hougard JM, Chandre F. Identification and geographic distribution of the ACE-1R mutation in the malaria vector Anopheles gambiae in south-western Burkina Faso, West Africa. Am J Trop Med Hyg. 2008;78:298-302.

36. Edi CVA, Koudou BG, Jones CM, Weetman D, Ranson H. Multiple-insecticide resistance in Anopheles gambiae mosquitoes, Southern Côte d'Ivoire. Emerg Infect Dis. 2012;18:1508-11.

37. Dabiré RK, Namountougou M, Diabaté A, Soma DD, Bado J, Toé HK, et al. Correction: Distribution and frequency of kdr mutations within Anopheles gambiae s.l. populations and first report of the ace.1G1195 mutation in Anopheles arabiensis from Burkina Faso (West Africa). PLoS One. 2015. doi:10. 1371/journal.pone.014164.

38. Dinham B. Growing vegetables in developing countries for local urban populations and export markets: Problems confronting small-scale producers. Pest Manage Sci. 2003;59:575-82.

39. Hodgson A. The high cost of pesticide poisoning in northern Ghana. Pest News. 2003;62:4

40. Hardy J. Apolipoprotein E, in the genetics and epidemiology of Alzheimer's disease. Am J Med Gen. 1995;60:456-60.

41. Pang G-F, Fan C-L, Chao Y-Z, Zhao T-S. Packed-column gas chromatographic method for the simultaneous determination of 10 pyrethroid insecticide residues in fruits, vegetables, and grains. J AOAC Int. 1994;77:738-47.

42. Ghana Statistical Service. Ghana Multiple Indicator Cluster Survey with an enhanced malaria module and biomarker Final report. Accra: GSS; 2011.

43. Ghana Statistical Service. Ghana demographic and health survey. Accra: GSS; 2004.

44. University of Ghana School of Public Health. Endline survey for affordable medicines facility for malaria intervention. Accra: SPH; 2012

45. National Malaria Control Programme. Strategic Plan for Malaria Control in Ghana 2014-2020. Accra; NMCP/MoH; 2014

46. President's Malaria Initiative-Malaria Operational Plan FY 2015in Ghana. Accra: PMl; 2015

47. Naing C, Ren WY, Man CY, Fern KP, Qiqi C, Ning CN, et al. Awareness of dengue and practice of dengue control among the semi-urban community: a cross sectional survey. J Community Health. 2011;36:1044-9.

48 Adasi, K. Studies on insecticide usage and pyrethroid resistance in populations of Anopheles gambiae sensu stricto (Diptera: Culic1 dae) in the Greater Accra Region of Ghana. 2001. http://hdl.handle.net/123456789/5113. Accessed 7 Nov 2016.

49. Loroño-Pino MA, García-Rejón JE, Machain-Williams C, Gomez-Carro S, Nuñez-Ayala G, del Rosario N-VM, et al. Towards a Casa Segura: a consumer product study of the effect of insecticide-treated curtains on Aedes aegypti and dengue virus infections in the home. Am J Trop Med Hyg. 2013;89: 385-97.

50. Pedra J, Mclntyre L, Scharf M, Pittendrigh BR. Genome-wide transcription profile of field-and laboratory-selected dichlorodiphenyltrichloroethane (DDT)-resistant Drosophila. Proc Natl Acad Sci U S A. 2004;101:7034-9.

51. Ranson H, N'Guessan R, Lines J, Moiroux N, Nkuni Z, Corbel V. Pyrethroid resistance in African anopheline mosquitoes: what are the implications for malaria control? Trends Parasitol. 2011;27:91-8

52. Committee on Gulf War Health. Gulf war and health: insecticides and solvents, vol. 2. Washington, D.C: National Academies Press; 2003.

\section{Submit your next manuscript to BioMed Central and we will help you at every step:}

- We accept pre-submission inquiries

- Our selector tool helps you to find the most relevant journal

- We provide round the clock customer support

- Convenient online submission

- Thorough peer review

- Inclusion in PubMed and all major indexing services

- Maximum visibility for your research

Submit your manuscript at www.biomedcentral.com/submit
Biomed Central 